\title{
PREVALÊNCIA DA BRUCELOSE E TUBERCULOSE BOVINA E PERCEPÇÃO DE RISCOS DE PEQUENOS PRODUTORES DE LEITE DO MUNICÍPIO DE PARANAIBA - MATO GROSSO DO SUL
}

\author{
(PREVALENCE OF BOVINE BRUCELLOSIS AND TUBERCULOSIS AND RISK PERCEPTION OF \\ DAIRY FARMERS FROM THE MUNICIPALITY OF PARANAIBA - MATO GROSSO DO SUL)
}

\section{G. L. PIVA FILHO ${ }^{1}$, L. H. QUEIROZ ${ }^{*}$}

Com o objetivo de avaliar a ocorrência da brucelose e da tuberculose bovina e a percepção de pequenos produtores de leite do município de Paranaiba, MS sobre o risco destas enfermidades para a saúde pública, foram visitadas 42 propriedades e aplicado um questionário para detectar as falhas no manejo sanitário que poderiam estar associados a ocorrência dessas enfermidades. Foram colhidas amostras de sangue de 378 vacas em lactação, de um total de 1.889 , as quais foram submetidas ao teste de triagem Antígeno Acidificado Tamponado e os reagentes foram confirmados pelo teste 2Mercaptoetanol para brucelose. Para tuberculose utilizou-se o Teste Cervical Simples para triagem e o Teste Cervical Comparativo como confirmatório dos inconclusivos. A prevalência tanto para a brucelose quanto para a tuberculose foi de $0,26 \%$ (1/378). Das 42 propriedades avaliadas, 26,2\% (11/42) destinam o leite à venda informal; 28,6\% (12/42) dos proprietários reconhece o leite como alimento passível de transmissão de zoonoses, porém 83,3\% (35/42) desconhecem o Programa Nacional de Controle e Erradicação da Brucelose e Tuberculose e nunca realizaram exames nos animais e $81 \%$ (34/42) não possui piquete de quarentena na propriedade. Os dados mostraram carências na percepção de riscos e manejos sanitários negligenciados. Integrar a educação sanitária no controle da brucelose e tuberculose contribuirá para que os produtores de leite adotem as medidas que permitirão mitigar os riscos à saúde animal e humana.

\footnotetext{
${ }^{1}$ Programa de Pós-graduação em Ciência Animal da Faculdade de Medicina Veterinária de Araçatuba, UNESP - Universidade Estadual Paulista.

${ }^{2}$ UNESP - Universidade Estadual Paulista, Faculdade de Medicina Veterinária de Araçatuba, Departamento de Apoio, Produção e Saúde Animal. 16050-680. Araçatuba, SP, Brasil. Email: lhqueiroz@fmva.unesp.br
} 